\title{
QUANTITATIVE TRAIT LOCI FOR BONE MINERAL DENSITY AND FEMORAL MORPHOLOGY IN AN ADVANCED INTERCROSS POPULATION OF MICE
}

\author{
Larry J. Leamy ${ }^{a,}$, , Scott A. Kelly ${ }^{b}, K^{\prime}$ unjie Hua ${ }^{c}$, Charles R. Farber $^{d, e}$, and Daniel Pomp ${ }^{c}$ \\ aDepartment of Biology, University of North Carolina at Charlotte, Charlotte, North Carolina, \\ 28223, USA \\ bepartment of Zoology, Ohio Wesleyan University, Delaware, Ohio, 43015, USA \\ 'Department of Genetics, University of North Carolina, Chapel Hill, North Carolina, 27599, USA \\ ${ }^{d}$ Center for Public Health Genomics, University of Virginia, Charlottesville, Virginia, 22908, USA \\ eDepartments of Medicine and Biochemistry and Molecular Genetics, University of Virginia, \\ Charlottesville, Virginia, 22908, USA
}

\begin{abstract}
Osteoporosis, characterized by low levels of bone mineral density (BMD), is a prevalent medical condition in humans. We investigated its genetic and environmental basis by searching for quantitative trait loci (QTLs) affecting six skeletal (including three BMD) traits in a $\mathrm{G}_{10}$ advanced intercross population produced from crosses of mice from the inbred strain C57BL/6J with mice from a strain selected for high voluntary wheel running. The mice in this population were fed either a high-fat or a matched control diet throughout the study, allowing us to test for QTL by diet interactions for the skeletal traits. Our genome scan uncovered a number of QTLs, the great majority of which were different from QTLs previously found for these same traits in an earlier $\left(\mathrm{G}_{4}\right)$ generation of the same intercross. Further, the confidence intervals for the skeletal trait QTLs were reduced from an average of $18.5 \mathrm{Mb}$ in the $\mathrm{G}_{4}$ population to an equivalent of about $9 \mathrm{Mb}$ in the $\mathrm{G}_{10}$ population. We uncovered a total of 50 QTLs representing 32 separate genomic sites affecting these traits, with a distal region on chromosome 1 harboring several QTLs with large effects on the BMD traits. One QTL was located on chromosome 5 at $4.0 \mathrm{Mb}$ with a confidence interval spanning from 4.0 to $4.6 \mathrm{Mb}$. Only three protein coding genes reside in this interval, and one of these, Cyp51, is an attractive candidate as others have shown that developing Cyp51 knockout embryos exhibit shortened and bowed limbs and synotosis of the femur and tibia. Several QTLs showed significant interactions with sex, although only two QTLs interacted with diet, both affecting only mice fed the high-fat diet.
\end{abstract}

\section{Keywords}

osteoporosis; femoral traits; bone morphology; diet

(C) 2012 Elsevier Inc. All rights reserved.

*Correspondence: Dr. Larry Leamy, Department of Biology, University of North Carolina at Charlotte, 9201 University City Blvd. Charlotte, NC 28223, USA, ljleamy@uncc.edu, Fax: 704-687-3128.

Publisher's Disclaimer: This is a PDF file of an unedited manuscript that has been accepted for publication. As a service to our customers we are providing this early version of the manuscript. The manuscript will undergo copyediting, typesetting, and review of the resulting proof before it is published in its final citable form. Please note that during the production process errors may be discovered which could affect the content, and all legal disclaimers that apply to the journal pertain. 


\section{Introduction}

Osteoporosis, characterized by low levels of bone mineral density (BMD), is a prevalent bone disease that exacts a considerable medical and financial toll on human society [1-3]. As a consequence, many studies have been devoted to elucidating the genetic and environmental basis of BMD and other measures of bone mass [4-8]. These investigations have shown that there is strong genetic control of osteoporosis [6,9], with heritability estimates for BMD typically varying from 0.6 to 0.8 [10-13] or even higher [14]. Consistent with this, increasing numbers of osteoporosis susceptibility genes have been identified in humans [15], although thus far their collective impact appears to be quite small [16].

Rodent models have proven particularly useful in investigating the genetics of BMD [17$20]$ and various measures of skeletal architecture [21,22]. For example, Ackert-Bicknell et al. [23] analyzed data from 11 different mouse studies, and identified 155 quantitative trait loci (QTLs) for BMD scattered throughout the genome. These investigators also found that 26 of 28 human BMD loci discovered via genome-wide association studies were concordant with mouse BMD QTLs [23]. Some candidate genes have emerged from fine-mapping of mouse BMD QTLs [18,24], and efforts are being made to understand the mechanisms by which they influence bone density $[25,26]$.

While many genes have been identified that may affect BMD levels, little is known about their potential interactions with any of a host of environmental factors such as smoking, alcoholism, diet, calcium intake, and physical activity [6]. There have been reports suggesting that the effects of genes for BMD may be modified by diet [for example, 27-29], but so far as is known, there has not been a comprehensive genome scan aimed at uncovering interactions of BMD genes with dietary differences. If interactions of BMD genes with factors such as diet prove to be extensive, it would suggest that the effects of these genes will need to be viewed in the context of the environment in which they operate.

In this study, we searched for QTLs affecting six skeletal (including three BMD) traits in a $\mathrm{G}_{10}$ advanced intercross population produced from crosses of mice with a genetic predisposition to dietary-induced obesity (C57BL/6J) with those in a strain selected for high voluntary wheel running. As detailed below, we were successful in discovering a number of QTLs for these skeletal traits, with the mapping precision enhanced by the accumulated recombinations in the $\mathrm{G}_{10}$ population. Farber et al. [22] previously found a number of QTLs for these traits in $\mathrm{G}_{4}$ mice from this same cross, and it therefore was of interest to compare our results with theirs to assess the extent of QTL replication. Because the $\mathrm{G}_{10}$ mice were fed either of two (control or high-fat) diets, it also was possible to test whether diet modified the effects of the QTLs on the skeletal traits.

\section{Materials and methods}

\subsection{The population, phenotyping, and genotyping}

We recently completed a QTL analysis of several body weight and composition traits in a $\mathrm{G}_{10}$ advanced intercross population of mice [30], and in this study we made use of these same mice to search for QTLs for skeletal traits. This population originated from crosses of inbred C57BL/6J (B6) female mice with male HR mice [31]. The HR strain was derived from a line of mice subjected to long-term artificial selection for high voluntary wheel running on days 5 and 6 after wheel exposure [32]. Rearing of the mice through the ninth generation was done as previously described [30,33], with pairs of mice in this generation crossed to produce up to two litters each in the $\mathrm{G}_{10}$ generation. By roughly four weeks of age, the $\mathrm{G}_{10}$ mice were randomly allocated into either a group fed a high-fat diet or a group fed a control diet (see Table 1 in Leamy et al. [30] for details of these diets). When the $G_{10}$ 
mice were from 59 to 65 days of age, they were individually exposed to running wheels during each of six consecutive days of access [33]. All mice were sacrificed shortly after the exercise period (at 59 to 65 days of age), tail clips were taken for later extraction of DNA, and the carcasses were stored at $-30^{\circ} \mathrm{C}$. All procedures were approved by the Institutional Animal Care and Use Committee at the University of North Carolina at Chapel Hill.

After the $\mathrm{G}_{10}$ mouse carcasses were thawed overnight, six skeletal traits were measured as previously described in detail by Farber et al. [22]. The traits included three areal bone mineral density (BMD) measures taken with a Lunar PIXimus II densitometer (GE Healthcare, Piscataway, NJ, USA): femoral BMD (FBMD), vertebral BMD (VBMD) and total BMD (TBMD). After all BMD measurements were completed, right femurs were removed from each mouse, and femoral length (FL), anteroposterior femoral width (AP), and mediolateral femoral width (ML) were measured with digital calipers to the nearest 0.01 $\mathrm{mm}$. Both AP and ML measurements were taken at mid-diaphysis just below the gluteal tuberosity [22]. For the three BMD traits, 466 mice were measured and available for analysis, including 230 males (114 in the control and 116 in the high-fat diet group) and 236 females (115 in the control and 121 in the high-fat diet group). Sample sizes for femoral length (total $=442)$ and the two femoral width traits (total $=454)$ were slightly less (see Table 1).

Genotyping of SNPs in each mouse was accomplished by the Mouse Universal Genotyping Array, MUGA [34]. We used a total of 2058 fully informative SNPs located throughout the genome, a list of which is provided in Appendix 1 of Leamy et al. [30]. The number of SNPs on each chromosome varied from 47 (chromosome 17) to 170 (chromosome 2), with an average intermarker distance of $1223 \mathrm{~kb}$ and a standard deviation of $1871 \mathrm{~kb}$. Additional details are given in Leamy et al. [30].

\subsection{Statistical analysis}

Prior to the QTL analyses, we first calculated basic statistics for each of the skeletal traits and examined their distributions after adjustment for appropriate sources of variation. For all six traits, adjustments were made for potential effects of sex, diet, age, litter size, cohort, and body weight at sacrifice. And for the three BMD traits, we included the $\mathrm{x}$ and $\mathrm{y}$ coordinates from the scans to correct for potential positioning effects for each mouse during the imaging process [22]. After these adjustments, five of the six skeletal traits exhibited normal distributions ( $P>0.05$ in Kolmogorov-Smirnov tests) whereas one trait, FL, showed significant platykurtosis. We also calculated correlations among the six (adjusted) skeletal traits (adjusted as described previously; [30]), and evaluated them for significance with the false-discovery-rate procedure [35].

We used the same procedure for mapping skeletal QTLs as we did previously to map QTLs for 10 body weight and composition traits in this same $\mathrm{G}_{10}$ mouse population [30]. This approach involved the use of the QTLRel program implemented in R that is especially appropriate for advanced intercross populations where there is inherent relatedness among individuals [36,37]. As before, we used the Haley-Knott interval mapping [38] option in this package that imputed genotypic values between any adjacent markers separated by more than $1 \mathrm{cM}$, effectively resulting in an increase in the total number of markers to 3023 . The model used in the QTLRel program included additive and dominance index values and the appropriate covariates for each trait as outlined above, and produced likelihood ratio values at each of the markers throughout the genome that were converted into LOD scores.

We calculated both 5\% experimentwise and 5\% chromosomewise thresholds for testing the significance of the LOD scores with the traditional permutation method (1000 replications) of Churchill and Doerge [39]. Chromosomewise values were used in our previous study [30] 
and were appropriate here as well because the 20 chromosomes are in linkage equilibrium and also differ in length and in the density of their markers. Further, for each trait only a single QTL among the 20 chromosomes is expected to exceed these chromosomewise threshold values by chance alone. This minimizes rare false positive results while potentially detecting additional true QTLs that would be missed using only the more stringent experimentwise threshold values [40-42]. Experimentwise threshold values ranged from 4.172 (AP) to 4.440 (FL), averaging 4.302. Chromosomewise threshold (suggestive) values were fairly similar for the six traits (means over all chromosomes varied from 2.79 to 2.86), although they exhibited more variability among the chromosomes (mean over all traits varied from 2.68 for chromosome 15 to 3.05 for chromosome 1).

The highest LOD scores on each chromosome that met or exceeded the chromosomewise levels of significance were considered to represent the sites of putative QTLs. If the LOD score distributions showed more than one peak exceeding the threshold value, the peaks were assumed to represent multiple QTLs if a drop of at least 1.5 LOD units separated them. Support intervals for each QTL were defined by 1.5 LOD drops on each side of the peak positions [43]. At each QTL site, QTLRel computed additive (a) and dominance genotypic values $(d)$ via partial regressions, and tested them for significance $(P<0.05)$ via individual $t$ tests. The additive genotypic value is defined as one-half the difference between the values for the two homozygotes, where positive values indicate that the HR allele increases, and negative values indicate that the HR allele decreases, the mean of the trait. The dominance genotypic value is defined as the difference between the mid-homozygous and the heterozygous values, and where significant, indicates that the QTLs exhibit dominance [44]. We also used QTLRel to estimate the percentage of the total phenotypic variation for the traits explained by each QTL.

At each of the sites of the QTLs discovered, we used an option in QTLRel that allowed us to test for potential interactions of the QTLs with sex and with diet. QTLRel calculated likelihood values in models run with and without sex (diet) by QTL interactions and generated a probability for the difference between the two models that we regarded as significant if it was less than 0.05 [30]. A significant sex by QTL or diet by QTL interaction was interpreted to mean that the genotypes affected the trait values differentially depending on the level of sex (males or females) or diet (control or high fat). Where found, we examined the effect of the QTL in the separate sexes or diets and used chromosomewise threshold LOD scores to assess significance.

Once all QTLs for the skeletal traits in the $\mathrm{G}_{10}$ mice were discovered, we were interested in assessing the extent of their replication with those found by Farber et al. [22] for these same traits in the $\mathrm{G}_{4}$ population of mice from the same original cross. However, the $\mathrm{G}_{4}$ mice were derived from both reciprocal mating types whereas our $\mathrm{G}_{10}$ mice were derived from only one mating type (B6 females X HR males). To appropriately assess QTL replication, therefore, we first conducted QTL analyses as before [22] for the six skeletal traits in the $\mathrm{G}_{4}$ population, but only for the mice produced from crosses of B6 females X HR males. Once the QTL sites in this new analysis were identified, we tested them for replication. This was done by testing for QTLs in the $\mathrm{G}_{10}$ mice using the procedures described above, but only for the SNPs closest to the sites of the $\mathrm{G}_{4}$ QTLs. Any sites with a LOD score of $1.30(P<0.05)$ or higher were assumed to indicate QTL replication $[45,46]$.

\section{Results}

\subsection{Basic Statistics}

Basic statistics for the six (unadjusted) skeletal traits in male and female $\mathrm{G}_{10}$ mice fed the control and the high-fat diet are given in Table 1. All values are shown for the separate sexes 
because of the multivariate significance of sex differences. Male mice show greater means than females in all cases, and these differences reached statistical significance $(P<0.05)$ in preliminary ANOVAs for four of these traits (all except ML and FBMD). Across both sexes, the means for all traits are similar for mice fed the high-fat compared to the control diet, differences being statistically significant only for ML.

Table 2 shows pairwise correlations among the six skeletal traits (all adjusted appropriately for the effects of sex, diet, etc.). All 15 correlations among the six skeletal traits measured in the $\mathrm{G}_{10}$ mice are positive in sign and 13 of the 15 values are significant. Most are moderate in magnitude, although the correlations of TBMD with both FBMD and VBMD are high $(+0.74$ and +0.78$)$.

\subsection{Skeletal QTLs}

Table 3 gives the basic statistics for all QTLs affecting the six skeletal traits in the $\mathrm{G}_{10}$ mice. A total of 50 QTLs were discovered, including thirteen that reached the experimentwise level of significance. The number of QTLs varies among the traits, being highest for TBMD (11) and lowest for FBMD (6). QTLs are found on 17 of the 20 chromosomes (all except chromosomes 6,13, and 18), with chromosome 1 (10 occurrences) easily being the most represented. QTLs on this chromosome affect 5 of the 6 traits, and show five separate peaks at 74.9-76.7 Mb, 156.8 Mb, 175.6-176.9 Mb, 185.6-188.1 Mb, and 191.6 Mb. Confidence intervals for the 50 QTLs average $13.6 \mathrm{Mb}$ with a standard deviation of $9.38 \mathrm{Mb}$.

Pleiotropy is evident for some of the QTLs affecting the skeletal traits. The four QTLs on chromosome 14 affecting VBMD, TBMD, AP, and ML, for example, all have similar locations (44.3 $\mathrm{Mb}$ to 49.1, see Figure 1) and may represent a single gene or set of closely linked genes with pleiotropic effects on these traits. Altogether, 32 of the 50 QTLs have non-overlapping confidence intervals, suggesting that there may be no more than 32 unique QTLs affecting these traits. The majority (23) of the 32 unique QTLs affect only one trait, however, so pleiotropy is not extensive.

Most (41) of the 50 skeletal QTLs exhibit significant additive genotypic effects, while only 14 show significant dominance effects. This disparity is produced primarily by the BMD traits, however, where all 26 QTLs affecting these traits show significant additive effects and only 4 exhibit significant dominance effects. The mean of the (absolute) additive values exhibited by the QTLs affecting these traits (0.0012) also is considerably higher than the mean of the (absolute) dominance values (0.00055). Among the QTLs affecting the three femoral morphometric traits, the proportions of QTLs exhibiting significant additive (15/24) and dominance effects $(10 / 24)$ are comparable $(P>0.05$ in a chi-square test). Consistent with this, the means of the absolute additive (0.051) and dominance effects (0.043) exhibited by these QTLs are similar in magnitude.

The percentage of the phenotypic variation explained by the skeletal QTLs ranges from $1.08 \%$ to $8.87 \%$, while averaging $2.4 \%$. The variation explained by the BMD QTLs (mean = $2.57 \%$ ) is comparable to that for the femoral QTLs $(2.12 \%)$. The highest percentages explained are seen for a QTL on chromosome 10 affecting ML (8.87\%), and two QTLs on chromosome 1 affecting VBMD (7.07\% and 6.00\%).

\subsection{Comparison with G4 results}

The results of the QTL reanalysis of the $\mathrm{G}_{4}$ mice produced only from crosses of B6 females $X$ HR males are shown in Table 4. To be consistent with the previous study [22], QTLs are listed for all LOD scores reaching the 0.05 or 0.1 experimentwise level of significance. Altogether, 24 QTLs were found on 11 different chromosomes, with an average confidence interval of $18.5 \mathrm{Mb}$. Tests at the sites of these $\mathrm{G}_{4}$ QTLs in the $\mathrm{G}_{10}$ population showed that 6 
produced significant LOD scores (bolded in Table 4), suggesting a QTL replication rate of $25 \%$. We also can directly compare locations of the $\mathrm{G}_{4}$ (Table 4) and $\mathrm{G}_{10}$ (Table 3) QTLs, and this shows that only 4 of the 24 total $\mathrm{G}_{4}$ QTLs (17\%) have confidence intervals that overlap with those of the $\mathrm{G}_{10}$ QTLs. Thus, the great majority of the $\mathrm{G}_{10}$ QTLs affecting the six skeletal traits we discovered do not replicate those found in the $\mathrm{G}_{4}$ mice. In addition, confidence intervals for the skeletal trait QTLs in the $\mathrm{G}_{10}$ population (Table 3) averaged 13.6 Mb (Table 5) compared to that of $18.5 \mathrm{Mb}$ for QTLs in the $\mathrm{G}_{4}$ population (Table 4). And this average of $13.6 \mathrm{MB}$ would have dropped to about $9 \mathrm{Mb}$ if we had used a 1-LOD (rather than 1.5-LOD) drop criterion as did Farber et al. [22].

\subsection{QTL interactions}

Nine skeletal QTLs in the $F_{10}$ population showed significant interactions with sex, including five with the BMD traits and four with the femoral traits. Four of the QTLs affecting the BMD traits are significant only in males, whereas two QTLs (affecting FL) are significant only in female mice. The three remaining QTLs show significant, but differential, effects in both sexes.

Only two QTLs, one on chromosome 19 affecting FL and one on chromosome 7 affecting AP, showed interactions with the dietary environment. Tests showed that the effects of both of these QTLs were significant only in mice fed the high-fat diet. As illustrated in Figure 2A, mice of all three genotypes at the chromosome 19 QTL fed the control diet show little difference in FL whereas HR/B6 and B6/B6 individuals fed the high-fat diet show a considerable increase in FL compared to HR/HR individuals. Similarly, a chromosome 7 QTL also has a significant effect on AP in mice fed the high-fat, but not the control diet (Figure 2B); although in this case HR/HR mice on the high-fat diet show the highest mean value.

\section{Discussion}

We undertook this study to discover QTLs for the six skeletal traits in mice in the $\mathrm{G}_{10}$ population, and to test whether their effects were modified by diet. We were successful in this regard, uncovering a total of 50 QTLs representing 32 separate genomic sites that were mapped with greater precision than was possible in the $\mathrm{G}_{4}$ population. Some of the skeletal QTLs replicated those found in the $\mathrm{G}_{4}$ population, but most were different. Further, several of these QTLs were sex-specific or showed differential effects in the two sexes, although only two exhibited significant interactions with the dietary environment.

\subsection{QTL replication}

We found a $25 \%$ replication rate for the $\mathrm{G}_{4}$ QTLs for the skeletal traits in our $\mathrm{G}_{10}$ mouse population (Table 4), lower than the $40 \%$ rate previously found for body weight and composition traits in this population [30]. As discussed by Leamy et al. [30], there are a number of possibilities for this lack of replication of some of the $\mathrm{G}_{4}$ QTLs. For example, some of the $\mathrm{G}_{4}$ QTLs may have marginally reached significance but randomly failed to do so in the $\mathrm{G}_{10}$ generation. Some $\mathrm{G}_{4}$ QTLs also may be false positives, or may be indicating linked genes that have separately mapped in the $\mathrm{G}_{10}$ population without reaching significance. And some of the replication failure may be due to the fact that one-half of the $\mathrm{G}_{10}$ mice were fed a high-fat diet whereas all $\mathrm{G}_{4}$ mice were fed a standard diet. Although this possibility is theoretically testable using the $\mathrm{G}_{10}$ mice fed only the control diet, the usefulness of such a test would be limited with the reduction in sample size and consequently also the statistical power to detect QTLs.

Leamy et al. [30] also suggested that some of the replication failure for the QTLs they found for body weight and composition traits may have resulted from sampling variation in 
reduced sample sizes for some genotypes produced from drift in the genotypic frequencies in the $\mathrm{G}_{10}$ mice. They tested this possibility by comparing the frequencies of the three genotypes at the markers closest to the sites of the QTLs that replicated versus those that did not replicate. This test in fact was statistically significant for their body weight and composition traits, and showed that the replicate QTLs tended to be associated with higher frequencies of the HR/HR genotype (and lower B6/B6 frequencies) compared with nonreplicate QTLs [30]. We performed this same test for the skeletal trait QTLs, and found that the frequencies of HR/HR, HR/B6, and B6/B6 genotypes for the replicate $(0.249,0.461$, and $0.290)$ and non-replicate QTLs $(0.229,0.483,0.288)$ were not significantly different $(P=$ $0.067)$. Thus it seems unlikely that genotypic drift accounts for the reduction in replication of the QTLs for the skeletal traits in the $\mathrm{G}_{10}$ mice.

\subsection{BMD QTLS}

While many of the QTLs for the BMD traits were different from those found in the $\mathrm{G}_{4}$ population, most are at similar locations as QTLs for these traits found in other studies. For example, the locations of 18 of the 26 QTLs for the three BMD traits (Table 3) are within the confidence intervals for previously-mapped mouse BMD QTLs listed by AckertBicknell et al. [23]. This also is the case for 8 of the 9 BMD QTLs reaching experimentwise significance, and even the single exception (a QTL on chromosome 4 affecting TBMD) has a confidence interval that overlaps with the confidence interval of a QTL for BMD [23]. This suggests that some of our QTLs may well be replicates of others previously discovered, although in many cases the congruence in mapping locations may be a simple consequence of the moderate to large confidence intervals often associated with BMD QTLs.

The BMD QTLs we found on chromosome 1 that had a particularly prominent effect on all three BMD traits may be the same as others previously uncovered in the distal region of this chromosome [18,20,47]. Recently Beamer et al. [18] used congenic B6.C3H mouse lines to refine the location of one of the BMD QTLs on chromosome 1 to an interval between 175.286 and $175.438 \mathrm{Mb}$, with expression data suggesting that $A C 084073.22$ is the most likely candidate gene for this QTL. It is therefore possible that this same gene may be underlying the QTLs we found for FBMD (176.9 Mb), VBMD (176.2 Mb), and TBMD $(175.6 \mathrm{Mb})$. On the other hand, other possibilities for these QTLs exist, including Darc $(175.26 \mathrm{Mb})$, a gene that has been found to influence BMD in B6.CAST-1 congenic mice by altering the rate of osteoclast formation [24], and both Ifi202 (175.9 Mb) and Ifi204 (175.7 $\mathrm{Mb}$ ) that have been associated with bone development $[26,48]$.

Another QTL more distally located on chromosome 1 also reached experimentwise significance for both VBMD (185.6 Mb) and TBMD (188.4), and nearly did so for FBMD (188.1). Tgfb2 (transforming growth factor, beta2) at $188.4 \mathrm{Mb}$ is a good candidate for these QTLs because this gene is known to promote osteoblast proliferation [49]. An even more distal QTL at 191.6 Mb significantly affected TBMD, although it is difficult to know whether it is truly distinct from the one at $188.4 \mathrm{Mb}$. This QTL disappeared when we reran the analysis using a drop of 2 (rather than 1.5) to separate adjacent peaks. Nonetheless, these several BMD QTL locations reflect the greater mapping precision of the $\mathrm{G}_{10}$ compared to that in the $\mathrm{G}_{4}$ population where only one QTL on distal chromosome 1 (at $179 \mathrm{Mb}$ ) was found to affect VBMD [22].

One QTL affecting VBMD was located on chromosome 5 at $4.0 \mathrm{Mb}$ with a confidence interval spanning from 4.0 to $4.6 \mathrm{Mb}$ (NCBI37/mm9). Only three protein coding genes reside in this interval: Akap9, Cyp51 and Gm9897. Cyp51 is an attractive candidate as it produces an enzyme that catalyzes the demethylation of lanosterol or 24,25

dihydrolanosterol in the cholesterol synthesis pathway [50]. Furthermore, developing Cyp51 knockout embryos exhibit shortened and bowed limbs and synotosis of the femur and tibia 
at E14.5 [51]. In an eQTL study with the $\mathrm{G}_{4}$ mice, Cyp51 was regulated by a significant eQTL in brain tissue as was Akap 9 in muscle tissue (Kelly and Pomp, personal communication). Further, perusal of the bioGPS database (http://biogps.org/ \#goto=welcome) suggests that expression levels of Akap 9 and $\mathrm{Gm} 9897$ are low and those for Cyp51 are high in both osteoclasts and osteoblasts. These data suggest that Cyp51 is the most likely candidate for the chromosome 5 QTL affecting VBMD; however, further work is needed confirm this hypothesis.

Given the moderate to high phenotypic correlations among the three BMD traits (Table 2), it was not surprising that there was evidence of pleiotropy among the QTLs affecting these traits. Further, the pleiotropic patterns tended to reflect those for the correlations, these being lowest for FBMD with VBMD $(r=0.56)$ and highest for FBMD and VBMD with TBMD (0.72 and 0.78). Thus 5 of the 6 QTLs for FBMD, and 6 of the 9 QTLs for VBMD, had confidence intervals that overlapped with QTLs for TBMD whereas only 3 of the 6 FBMD QTLs appear to be the same as those affecting VBMD. This implies that there is a combination of both common and independent genes that control BMD levels at separate anatomical sites. Estimates of genetic correlations between human BMD levels in the spine, hip, and ultradistal radius [52] and between the lumbar spine and femoral neck [53] are moderate to high in magnitude, this also suggesting some commonality in the genetic control of BMD in different regions.

\subsection{Femoral QTLs}

Although genetic studies of femoral size and shape are not as numerous as those of BMD, some of the femoral QTLs previously uncovered are in similar locations to those we discovered in the $\mathrm{G}_{10}$ mouse population. Using the Mouse Genome Informatics database (www.informatics.jax.org), we found QTLs for femoral/long bone traits that are close to the locations for 6 of the 7 QTLs for AP. This includes the only QTL (on chromosome 1) reaching experimentwise significance that is precisely at the same site $(74.9 \mathrm{Mb})$ as $L b n 1$, a QTL affecting long bones in mice [54,55]. Indian hedgehog (Ihh) at $75.0 \mathrm{Mb}$ on this chromosome appears to be a likely possibility for this QTL since this gene has known effects on osteoblast development in endochondral bones [56]. We also found previouslymapped QTLs for femoral traits that were similar in location to 6 of the 9 QTLs we mapped for ML. The QTL for ML on chromosome 8 at $98.2 \mathrm{Mb}$ (Table 3) is of particular interest because its confidence interval includes a QTL that Farber et al. [22] found for this trait in the $\mathrm{G}_{4}$ mice. Based on gene expression data from osteoblasts and osteoclasts, Farber et al. [22] suggested that Cadherin 11 (Cdh11), is a strong candidate gene for their QTL, and it is a candidate for the QTL we found as well.

We also uncovered another ML QTL on chromosome 8 (94.7 Mb, CI: 91.5-96.7 Mb) that exhibited the highest LOD score. Although no other limb bone QTLs appear to match this location, we did previously find a QTL on chromosome 8 at a similar location $(89.8 \mathrm{Mb}$; confidence intervals overlap) that strongly affected the post-exercise percentage of fat and lean tissue in this population of mice [30]. It therefore is possible that the gene underlying this QTL has pleiotropic effects on the percentage of both fat and lean tissue as well as ML. ML does correlate with both the percentage of fat $(r=-0.27 ; P<0.001)$ and lean tissue $(r=$ $+0.22 ; P<0.001)$ in the $\mathrm{G}_{10}$ mice, and interestingly, there is a gene (Fto) at $93.8 \mathrm{Mb}$ on chromosome 8 that affects body weight, adipose tissue, and metabolism [57]. A significant cis eQTL (LOD = 10.4) was also mapped for this gene in muscle tissue (triceps surae) of the $\mathrm{G}_{4}$ population of mice (Kelly and Pomp, personal communication).

We identified 8 QTLs for FL, none of which corresponded to the two QTLs for this trait listed by Farber et al. [22] in the $\mathrm{G}_{4}$ mice. We did find previous QTLs for FL or associated bone traits that were in similar locations for four of the 8 QTLs we discovered for this trait 
in the $\mathrm{G}_{10}$ mice, but these did not include the only QTL (on chromosome 16 at $36.2 \mathrm{Mb}$ ) that reached experimentwise significance. Protein-coding genes in the confidence interval for this QTL include Casr (calcium-sensing receptor) at $36.5 \mathrm{Mb}$. Casr would seem to be an excellent candidate for this QTL because mutants produce altered levels of serum calcium and parathyroid hormone, resulting in bone defects [58].

\subsection{QTL Interactions}

It was not surprising that we discovered several significant interactions with sex among the QTLs affecting the BMD traits given that previous studies have uncovered a number of BMD QTLs in various mouse populations with sex-dependent effects $[23,44]$. It was interesting that four of the five QTLs showing sex interactions for the BMD traits were male-specific, three of these four residing on chromosome 1. Beamer et al. [44] also found male-specific QTLs in this same general region on chromosome 1 for BMD traits in their mouse population. Among the femoral QTLs, two affecting FL were female-specific, including one on chromosome 16 that reached experimentwise significance (Table 3). This result increases the plausibility of Calcium sensing receptor as a candidate for this QTL because Cheng et al. [59] showed that heterozygous knockouts of this gene produced bone changes in female, but not male, mice.

We found that just two of the 50 total QTLs, one affecting FL and one affecting AP, also interacted with diet. This proportion if much lower than that of 9 of 19 QTLs for FL that Norgard et al. (2011) found interacting with diet in an $\mathrm{F}_{34}$ advanced intercross population of mice. However, the mice in that study were fed either a high-fat or a control diet for 20 weeks as compared to the roughly five weeks of exposure we used. We did find 6 QTL by diet interactions among 24 QTLs affecting post-exercise body weight and the percentage of fat and lean tissue in our previous study using the $F_{10}$ mice [30], suggesting that QTLs for these sorts of traits may be more susceptible to differences in the dietary environment than those governing bone traits. Norgard et al [60] also found this same pattern in comparisons of dietary effects on QTLs for limb bone lengths versus those for obesity-related traits in their mouse population.

It is difficult to know what genes might be reasonable candidates for the two QTLs we discovered that interacted with diet, especially given the many possibilities in the confidence intervals for these QTLs. There appear to be very few reports of QTLs for limb traits in these specific locations on chromosome 7 and 19 [60], however, suggesting that the primary action of the genes underlying these QTLs may be on other traits such as overall size, growth, or metabolism that are more clearly dependent on diet, but also with pleiotropic effects on FL and AP. As an example, Prcp (prolylcarboxypeptidase, angiotensinase C) is a gene located on chromosome 7 (at $92.9 \mathrm{Mb}$ ) that when mutant results in lean and short mice with decreased food intake that are resistant to obesity induced by a high-fat diet [61]. This gene exhibited significant expression in brain tissue in the $\mathrm{G}_{4}$ mice [62], and clearly represents an attractive candidate for a QTL we previously found on chromosome 7 (at 94.8) that affected the percentage of lean tissue in the $\mathrm{G}_{10}$ mice variably depending on diet [30]. But it is easy to imagine that it also may a candidate for the diet-dependent QTL on this chromosome (at 89.1) affecting AP (see Figure 2B). Further work will be required to isolate these and other diet-dependent genes before we can understand the mechanisms involved in their responses to dietary differences and assess their role in the formation of bone as well as bone diseases such as osteoporosis.

\section{Acknowledgments}

We gratefully acknowledge Theodore Garland, Jr., University of California-Riverside, for providing the original HR mice that contributed to creation of the $\mathrm{G}_{10}$ population. It is a pleasure to thank Riyan Cheng for assistance in 
implementing the R/QTLRel program used in the analysis of the data. We also acknowledge Daniel Yu (University of Virginia) and Elnaz Balakhanlou for assisting with data collection. Two anonymous reviewers also provided very useful suggestions for revision of the original draft of this paper. This work was partially supported by National Institutes of Diabetes and Digestive and Kidney Diseases Grant DK-076050 to D Pomp and AR-057759 to C Farber. Phenotypes were collected with the Animal Metabolism Phenotyping core facility within UNC's Nutrition and Obesity Research Center (funded by National Institute of Diabetes and Digestive and Kidney Diseases Grant P30DK056350).

\section{References}

1. Hui SL, Slemenda CW, Johnston CC. Age and bone mass as predictors of fracture in a prospective study. J Clin Invest. 1988; 81:1804-1809. [PubMed: 3384952]

2. Looker AC, Orwoll ES, Johnston CC Jr, Lindsay RL, Wahner HW, Dunn WL, Calvo MS, Harris TB, Heyse SP. Prevalence of low femoral bone density in older U.S. adults from NHANES III. J Bone Miner Res. 1997; 12:1761-1768. [PubMed: 9383679]

3. Cummings SR, Melton LJ II. Epidemiology and outcomes of osteoporotic fractures. Lancet. 2002; 359:1761-1767. [PubMed: 12049882]

4. Mitchell BD, Kammerer CM, Schneider JL, Perez R, Bauer RI. Genetic and environmental determinants of bone mineral density in Mexican Americans: results from the San Antonio family osteoporosis study. Bone. 2003; 33:839-846. [PubMed: 14623060]

5. Lau HH, Hy MY, Ho AY, Luk KD, Kung AW. Genetic and environmental determinants of bone mineral density in Chinese women. Bone. 2005; 36:700-709. [PubMed: 15781005]

6. Kung AWC, Huang QY. Genetic and environmental determinants of osteoporosis. J Musculoskel Neuron Inter. 2007; 7:26-32.

7. Ongphiphadhanakul B. Osteoporosis: the role of genetics and the environment. Forum Nutr. 2007; 60:158-167. [PubMed: 17684412]

8. Musumeci M, Vadala G, Tringali G, Insirello E, Roccazzello AM, Simpore J, Musumeci S. Genetic and environmental factors in human osteoporosis from Sub-Saharan to Mediterranean areas. J Bone Miner Metab. 2009; 27:424-434. [PubMed: 19255718]

9. Peacock M, Turner CH, Econs MJ, Foroud T. Genetics of osteoporosis. Endocrinol Rev. 2002; 23:303-326.

10. Krall EA, Dawson-Hughes B. Heritable and life-style determinants of bone mineral density. J Bone Miner Res. 1993; 9:1-9. [PubMed: 8427042]

11. Eisman JA. Genetics of osteoporosis. Endocrinol Rev. 1999; 20:788-804.

12. Prentice A. The relative contribution of diet and genotype to bone development. P Nutr Soc. 2001; 60:45-52.

13. Brown LB, Streeten EA, Shuldiner AR, Almalsy LA, Peyser PA, Mitchell BD. Assessment of sexspecific genetic and environmental effects on bone mineral density. Genet Epidemiol. 2004; 27:153-161. [PubMed: 15305331]

14. Brown LB, Streeton EA, Shapiro JR, McBride D, Shuldiner AR, Peyser PA, Mitchell BD. Genetic and environmental influences on bone mineral density in pre- and post-menopausal women. Osteoporosis Int. 2005; 16:1849-1856.

15. Estrada K, Sltykarsdottir U, Evangelou E, Hsu Y-H, Duncan EL, Ntzan EE, Oi L, Albagha OM, Amin N, Kemp JP, Koller DL, Li G, Liu C-T, Minster RL, Moayyeri A, Vandenput L, Willner D, Xiao S-M, Yerges-Armstrong LM, Zheng H-F, Alonso N, Eriksson J, Kammerer CM, Kaptoge SK, Leo PJ, et al. Genome-wide meta-analysis identifies 56 bone mineral density loci and reveals 14 loci associated with risk of fracture. Nat Genet. 2012; 44:491-501. [PubMed: 22504420]

16. Rivadeneira F, Styrkarsdottir U, Estrada K, Halldorsson BV, Hsu YH, Richards JB, Zillikens MC, Kavvoura FK, Amia H, Aulchenko YS, Cupples LA, Deloukas P, Demissie S, Grundberg E, Hofman A, Kong A, Karsik D, van Meurs JB, Ostra B, Pastinen T, Pols HA, Sigurdsoon G, Soranzo N, Thorleifsson G, Thorsteinsdottir U, Williams FM, Wilson SG, Zhou Y, Ralston SH, van Duijn CM, Spector T, Kiel DP, Stefansson K, Ioannidis JP, Uintterlinden AG. Twenty bonemineral-density loci identified by large-scale meta-analysis of genome-wide association studies. Nat Genet. 2009; 41:1199-1206. [PubMed: 19801982] 
17. Beamer WG, Shultz KL, Donahue LR, Churchill GA, Sen S, Wergedal JR, Baylink DJ, Rosen CJ. Quantitative trait loci for femoral and lumbar vertebral bone mineral density in C57BL/6J and C3H/HeJ inbred strains of mice. J Bone Miner Res. 2001; 16:1195-1206. [PubMed: 11450694]

18. Beamer WG, Shultz KL, Coombs HF III, DeMambro VE, Reinholdt LG, Ackert-Bicknell CL, Canalis E, Rosen CJ, Donahue LR. BMD regulation on mouse distal chromosome 1, candidate genes, and response to ovariectomy or dietary fat. J Bone Miner Res. 2011; 26:88-99. [PubMed: 20687154]

19. Farber CR, van Has A, Ghazalpour A, Aten JE, Doss S, Sos B, Schadt EE, Ingram-Drake L, Davis RC, Horvath S, Smith DJ, Drake TA, Lusis AJ. An integrative genetics approach to identify candidate genes regulating BMD: combining linkage, gene expression and association. J Bone Miner Res. 2009; 24:105-116. [PubMed: 18767929]

20. Xiong Q, Jiao Y, Hasty KA, Canale ST, Stuart JM, Beamer WG, Deng HW, Baylink D, Gu W. Quantitative trait loci, genes, and polymorphisms that regulate bone mineral density in mouse. Genomics. 2009; 93:401-414. [PubMed: 19150398]

21. Klein RF, Turner RJ, Skinner LD, Vartanian KA, Serang M, Carlos AS, Shea M, Belknap JK, Orwoll ES. Mapping quantitative trait loci that influence femoral cross-sectional area in mice. J Bone Miner Res. 2002; 17:1752-1760. [PubMed: 12369778]

22. Farber CR, Kelly SA, Baruch E, Yu D, Hua K, Nehrenberg DL, de Villena FP-M, Buus RJ, Garland T Jr, Pomp D. Identification of quantitative trait loci influencing skeletal architecture in mice: emergence of $C d h 11$ as a primary candidate gene regulating femoral morphology. J Bone Miner Res. 2011; 9:2174-2183. [PubMed: 21638317]

23. Ackert-Bicknell CL, Karasik D, Li Q, Smith RV, Hsu Y-H, Churchill GA, Paigen BJ, Tsaih S-W. Mouse BMD quantitative trait loci show improved concordance with human genome-wide association loci when recalculated on a new, common mouse genetic map. J Bone Miner Res. 2010; 25:1808-1820. [PubMed: 20200990]

24. Edderkaoui B, Baylink DJ, Beamer WG, Wergedal JE, Porte R, Chaudhuri A, Mohan S. Identification of mouse Duffy antigen receptor for chemokines (Darc) as a BMD QTL gene. Genome Res. 2007; 17:577-585. [PubMed: 17416748]

25. Liu CJ, Chang E, Yu J. The interferon-inducible p204 protein acts as a transcriptional coactivator of Cbfa1 and enhances osteoblast differentiation. J Biol Chem. 2005; 280:2788-2796. [PubMed: 15557274]

26. Kong L, Liu C. Medication of chrondrogenic and osteogenic differentiation by an interferon inducible p202 protein. Cell Mol Life Sci. 2008; 65:3494-3506. [PubMed: 18791844]

27. Le P, Kawai M, Bornstein S, DeMambro VE, Horowitz MC, Rosen CJ. A high-fat diet induces bone loss in mice lacking the Alox 5 gene. Endocrinology. 2012; 153:6-16. [PubMed: 22128029]

28. Ackert-Bicknell CL, Demissie S, de Evsikova CM, Hsu YH, DeMambro VE, Karasik D, Cupples LA, Ordovas JM, Tucker KL, Cho K, Canalis E, Paigen B, Churchill GA, Forejt J, Beamer WG, Ferrari S, Bouxsein ML, Kiel DP, Rosen CJ. PPARG by dietary fat interaction influences bone mass in mice and humans. J Bone Miner Res. 2008; 23:1398-1408. [PubMed: 18707223]

29. Norgard E, Lawson H, Pletscher L, Wang B, Brooks V, Wolf J, Cheverud J. Genetic factors and diet affect long-bone length in the F34 LG, SM advanced intercross. Mamm Genome. 2011; 22:178-196. [PubMed: 21170743]

30. Leamy LJ, Kelly SA, Hua K, Pomp D. Exercise and diet affect quantitative trait loci for body weight and composition traits in an advanced intercross population of mice. Physiol Genomics. 2012; 44:1141-1153. [PubMed: 23048196]

31. Kelly SA, Nehrenberg DL, Hua K, Garland T Jr, Pomp D. Exercise, weight loss, and changes in body composition in mice: phenotypic relationships and genetic architecture. Physiol Genomics. 2011; 43:199-212. [PubMed: 21156834]

32. Swallow JG, Carter PA, Garland T Jr. Artificial selection for increased wheel-running behavior in house mice. Behav Genet. 1998; 28:227-237. [PubMed: 9670598]

33. Kelly SA, Nehrenberg DL, Peirce JL, Hua K, Steffy BM, Wiltshire T, Pardo-Manuel de Villena F, Garland T Jr, Pomp D. Genetic architecture of voluntary exercise in an advanced intercross line of mice. Physiol Genomics. 2010; 42:190-200. [PubMed: 20388837] 
34. Collaborative Cross Consortium. The genome architecture of the collaborative cross mouse genetic reference population. Genetics. 2012; 90:389-401.

35. Benjamini Y, Hochberg Y. Controlling the false discovery rate: a practical and powerful approach to multiple testing. JR Stat Soc B. 1995; 57:289-300.

36. Cheng R, Abney M, Palmer PP, Skol AD. QTLRel: an R package for genome-wide association studies in which relatedness is a concern. BMC Genet. 2011; 12:66. [PubMed: 21794153]

37. Cheng R, Lim JE, Samocha KE, Sokoloff G, Abney M, Skol AD, Palmer AA. Genome-wide association studies and the problem of relatedness among advanced intercross lines and other highly recombinant populations. Genetics. 2010; 185:1033-1044. [PubMed: 20439773]

38. Haley CS, Knott SA. A simple regression technique for mapping quantitative trait loci in line crosses using flanking markers. Heredity. 1992; 69:315-324. [PubMed: 16718932]

39. Churchill GA, Doerge RW. Empirical threshold values for quantitative trait mapping. Genetics. 1994; 138:963-971. [PubMed: 7851788]

40. Weller JI, Song JZ, Heyen DW, Lewin HA, Ron M. A new approach to the problem of multiple comparisons in the genetic dissection of complex traits. Genetics. 1998; 150:1699-1706. [PubMed: 9832544]

41. Rao DC. CAT scans, PET scans, and genomic scans. Genet Epidemiol. 1998; 15:1-18. [PubMed: 9523207]

42. Cheverud JM, Vaughn TT, Pletscher LS, Peripato AC, Adams ES, Erikson CF, King-Ellison KJ. Genetic architecture of adiposity in the cross of LG/J and SM/J inbred mice. Mamm Genome. 2001; 12:3-12. [PubMed: 11178736]

43. Manichaikul A, Dupuis J, Sen S, Broman KW. Poor performance of bootstrap confidence intervals for the location of a quantitative trait locus. Genetics. 2006; 174:481-489. [PubMed: 16783000]

44. Falconer, DS.; Mackay, TFC. Introduction to Quantitative Genetics. 4. Longman; England: 1996.

45. Vaughn TT, Pletscher LS, Peripato A, King-Ellison K, Adams E, Erikson C, Cheverud JM. Mapping quantitative trait loci for murine growth: a closer look at genetic architecture. Genet Res. 1999; 74:313-322. [PubMed: 10689807]

46. Ehrich TH, Hrbek T, Kenney-Hunt JP, Pletscher LS, Wang B, Semenkovich CF, Cheverud JM. Fine-mapping gene-by-diet interactions on chromosome 13 in a LG/J X SM/J murine model of obesity. Diabetes. 2005; 54:1863-1872. [PubMed: 15919810]

47. Beamer WG, Shultz KL, Ackert-Bicknell CI, Horton LG, Delahunty KM, Coombs HF III, Donahue LR, Canalis E, Rosen CJ. Genetic dissection of mouse distal chromosome 1 reveals three linked BMD QTLs with sex-dependent regulation of bone phenotypes. J Bone Miner Res. 2007; 22:1187-1196. [PubMed: 17451375]

48. Luan Y, Yu XP, Xu K, Ding B, Yu J, Huang Y, Yang N, Lengvel P, DiCesare PE, Liu CJ. The retinoblastoma protein is an essential mediator of osteogenesis that links the p204 protein to the Cbfa1 transcription factor thereby increasing its activity. J Biol Chem. 2007; 282:16860-16870. [PubMed: 17439944]

49. Mohan S, Baylink DJ. Bone growth factors. Clin Orthop. 1991; 263:30-48. [PubMed: 1993386]

50. Stromstedt M, Rozman D, Waterman MR. The ubiquitously expressed human CYP51 encodes lanosterol 14 alpha-demethylase, a cytochromome $\mathrm{P} 450$ whose expression is regulated by oxysterols. Arch Biochem Biophys. 1996; 329:73-81. [PubMed: 8619637]

51. Keber R, Motain H, Wagner KD, Debeljak N, Rassoulzadegan M, Acimovic J, Rozman D, Horvat $\mathrm{S}$. Mouse knockout of the cholesterogenic cytochrome P450 lanosterol 14alpha-demethylase (Cyp51) resembles Antley-Fixler syndrome. J Biol Chem. 2011; 286:29086-29087. [PubMed: 21705796]

52. Yang TL, Zhao LJ, Lin YJ, Recker RR, Deng HW. Genetic and environmental correlations of bone mineral density at different skeletal sites in females and males. Calcified Tissue Int. 2006; 78:212217.

53. Livshits G, Deng HW, Nguyen TV, Yakovenko K, Recker RR, Eisma JA. Genetics of bone mineral density: evidence for a major pleiotropic effect from an intercontinental study. J Bone Miner Res. 2004; 19:914-923. [PubMed: 15125790] 
54. Kenney-Hunt J, Wang B, Norgard E, Fawcett G, Galk D, Pletscher L, Jarvis J, Roseman C, Wolf J, Cheverud J. Pleiotropic patterns of quantitative trait loci for 70 murine skeletal traits. Genetics. 2008; 178:2275-2288. [PubMed: 18430949]

55. Norgard EA, Jarvis JP, Roseman CC, Maxwell TJ, Kenney-Hunt JP, Samocha KE, Pletscher LS, Wang B, Fawcett GL, Leatherwood CJ, Wolf JB, Cheverud JM. Replication of long-bone length QTL in the F9-F10 LG, SM advanced intercross. Mamm Genome. 2009; 20:224-235. [PubMed: 19306044]

56. Echelard Y, Epstein DJ, St-Jacques B, Shen L, Mohler J, McMahon JA, McMahon AP. Sonic hedgehog, a member of a family of putative signaling molecules, is implicated in the regulation of CNS polarity. Cell. 1993; 75:1417-1430. [PubMed: 7916661]

57. Peters T, Ausmeier K, Ruther U. Cloning of Fatso (Fto), a novel gene deleted by the Fused toes (Ft) mouse mutation. Mamm Genome. 1999; 10:983-986. [PubMed: 10501967]

58. Xue Y, Xiao Y, Liu J, Karaplis AC, Pollar MR, Brown EM, Miao D, Goltzman D. The calciumsensing receptor complements parathyroid hormone-induced bone turnover in discrete skeletal compartments in mice. Am J Physiol-Endoc M. 2012; 302:E841-851.

59. Cheng Z, Liang N, Liang N, Chen TH, Li A, Maria CS, You M, Ho H, Song F, Bikle D, Tu C, Shoback D, Chang W. Sex and age modify biochemical and skeletal manifestations of chronic hyperparathyroidism by altering target organ responses to $\mathrm{Ca}^{2+}$ and PTH in mice. J Bone Miner Res. 201210.1002/jbmr.1846

60. Norgard EA, Roseman CC, Fawcett GL, Pavlicev M, Morgan CD, Pletscher LS, Wang B, Cheverud JM. Identification of quantitative trait loci affecting murine long bone length in a twogeneration intercross of LG/J and SM/J mice. J Bone Miner Res. 2008; 23:887-895. [PubMed: 18435578]

61. Wallingford N, Perroud B, Gao Q, Coppola A, Gyengesi E, Liu ZW, Gao XB, Diament A, Haus KA, Shariat-Madar Z, Mahdi F, Wardlaw SL, Schmaier AH, Warden CH, Diano S.

Prolycarboxpeptidase regulates food intake by inactivating alpha-MSH in rodents. J Clin Invest. 2009; 119:2291-2303. [PubMed: 19620781]

62. Kelly SA, Czech PP, Wight JT, Blank KM, Garland T Jr. Experimental evolution and phenotypic plasticity of hindlimb bones in high-activity house mice. J Morphol. 2006; 267:360-374. [PubMed: 16380968] 


\section{Highlights}

- We uncovered 50 quantitative trait loci (QTLs) affecting six skeletal traits in an intercross population of mice.

- Several QTLs on distal chromosome 1 had large effects on the bone mineral density (BMD) traits.

- Cyp51 is an attractive candidate for a BMD QTL located on chromosome 5.

- Diet and sex altered the presence and/or effects of some of the skeletal QTLs. 


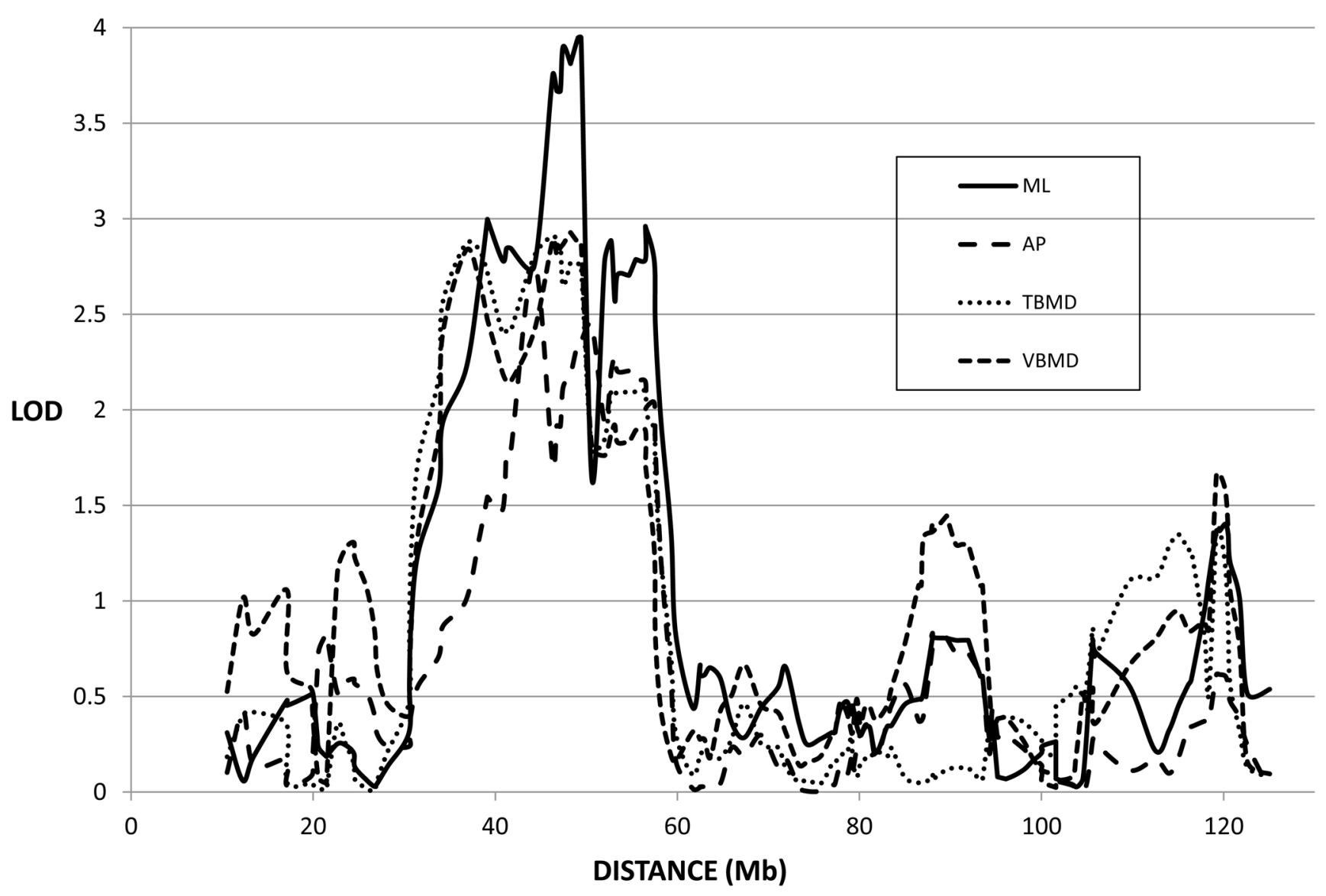

Figure 1.

Plot of the LOD scores for VBMD, TBMD, AP, and ML on chromosome 14. 
A

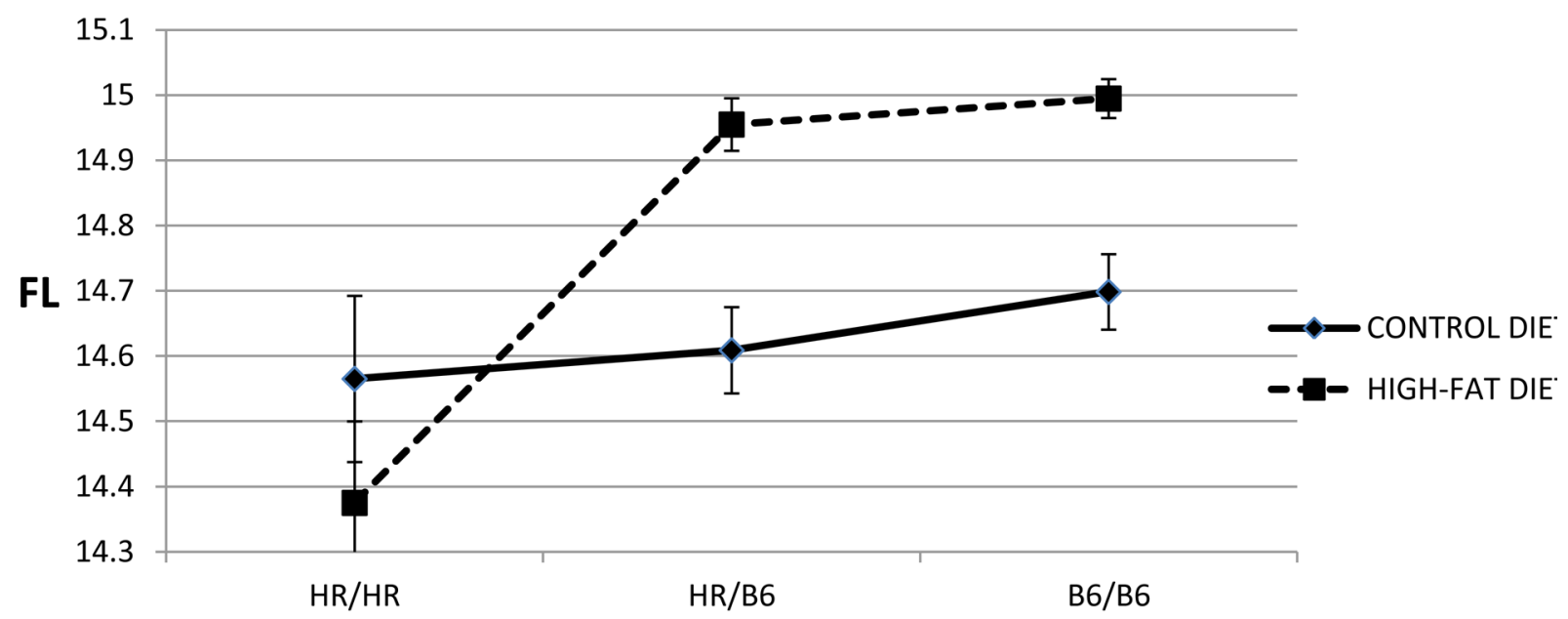

Chromosome 19 at 24.3 Mb

B

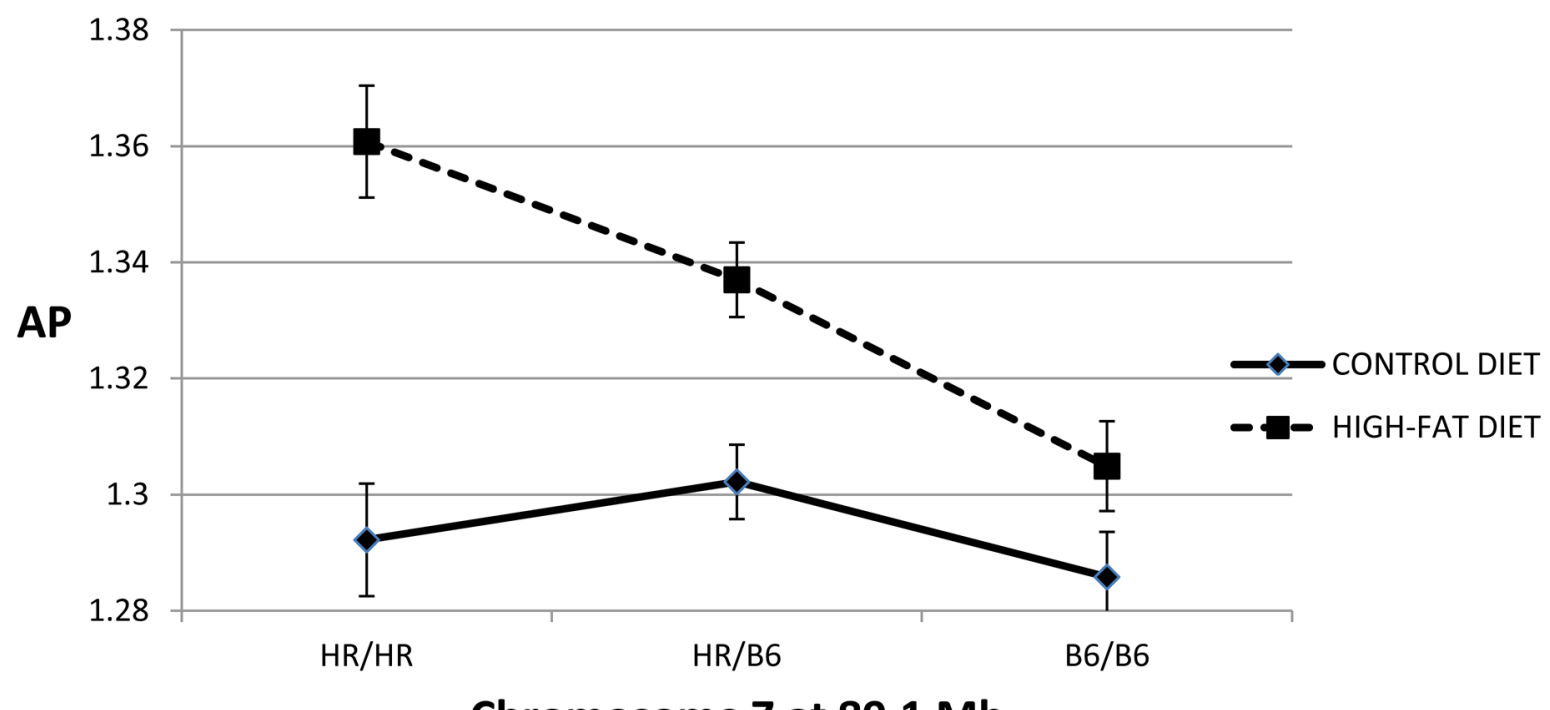

Chromosome 7 at $89.1 \mathrm{Mb}$

Figure 2.

Mean genotypic values (with standard errors) of a QTL on chromosome 19 affecting FL (A) and a QTL on chromosome 7 affecting AP (B), that vary depending on the diet. 


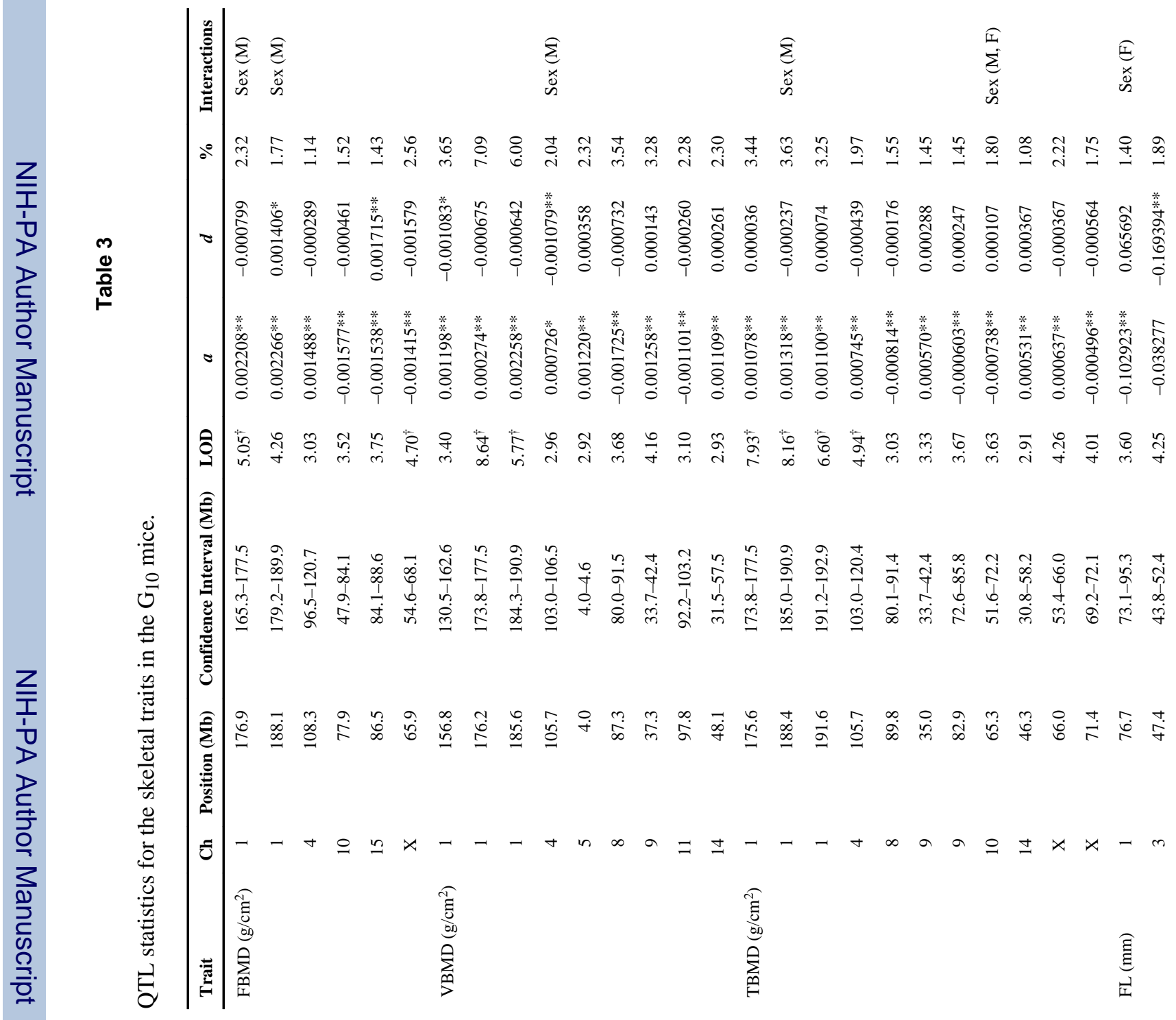




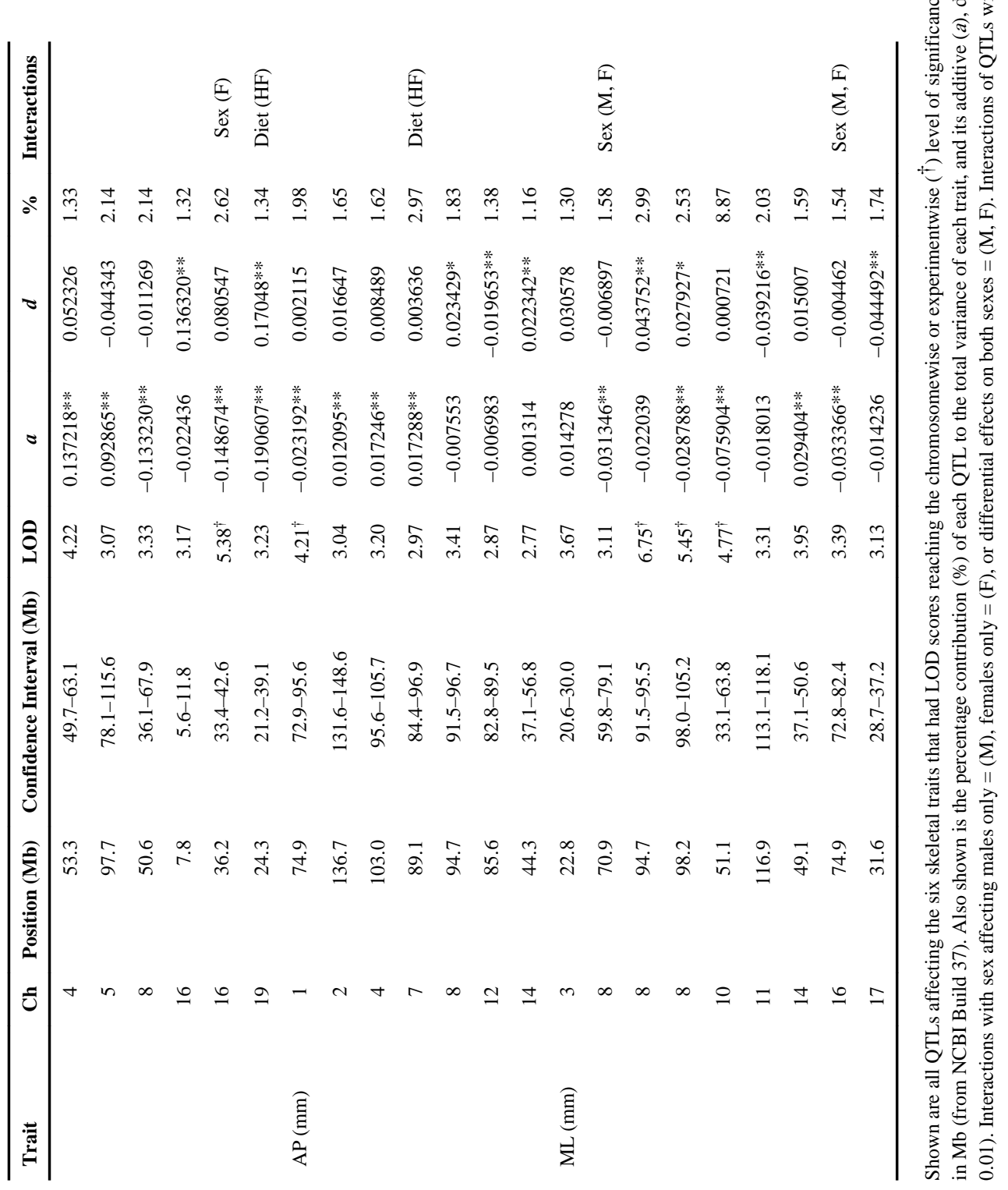




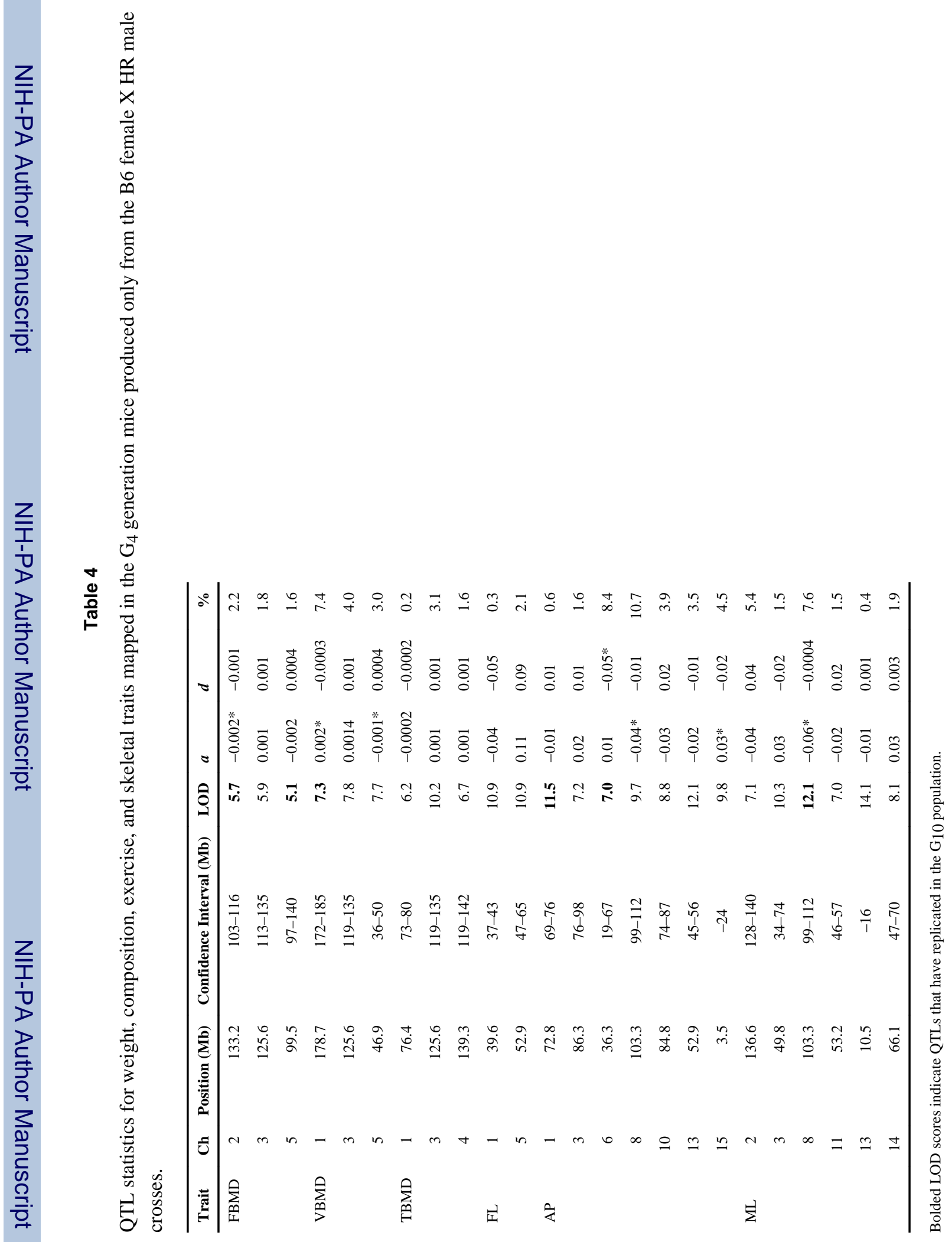

